\title{
THE EFFECT OF ALCOHOL ON THE RENAL EXCRETION OF WATER AND ELECTROLYTE ${ }^{1}$
}

\author{
By MAURICE B. STRAUSS, ${ }^{2}$ JACK D. ROSENBAUM, ${ }^{3}$ AND \\ WILLIAM P. NELSON, III 4 \\ (From the Medical Service, Cushing Veterans Administration Hospital, \\ Framingham, Mass.)
}

That the ingestion of alcohol-containing beverages provokes an increased flow of urine was no doubt a matter of common observation even before Shakespeare commented upon it (1). However, the diuretic effect of alcohol is dismissed in recent textbooks $(2,3)$ with the statement that the increase in urinary output is largely due to the quantity of fluid imbibed with the alcohol.

Although Simanowsky (4) in 1886 reported that a liter of beer provoked a greater diuretic response than a similar quantity of water, Raphael failed to confirm this a decade later (5). The matter then rested until 1910 when Mendel and Hilditch (6) administered a standardized daily diet to two volunteers and following several days of observation gave $16 \mathrm{ml}$. of 95 per cent alcohol with each meal and also at 10:30 a.m., 3:30 p.m. and 10:00 p.m., in each instance the alcohol being mixed with milk or water. There was no greater urine output on the alcohol than the control days. However, Miles (7) clearly demonstrated in 1922 that a single dose of $27.5 \mathrm{gm}$. of alcohol in $100 \mathrm{ml}$. of fluid definitely increased the flow of urine and similar observations are recorded in a number of studies reviewed in 1940 by Bruger (8). The diuresis has in general been ascribed to a direct action of alcohol on the kidney or its circulation. In 1938 Nicholson and Taylor (9) performed the first experiments in which excretion of electrolyte was studied in detail. They employed 136 to $161 \mathrm{gm}$. of alcohol ingested during a period of eight hours. The authors state that during the

\footnotetext{
1 Reviewed in the Veterans Administration and published with the approval of the Chief Medical Director. The statements and conclusions published by the authors are the result of their own study and do not necessarily reflect the opinion or policy of the Veterans Administration.

2 Chief, Medical Service.

3 Assistant Chief, Medical Service and Director, Research Laboratory.

4 Resident in Medicine.
}

first four hours of alcohol ingestion there was a water diuresis with retention of sodium, potassium and chloride and that during the second four hours only very small amounts of urine were voided. However, no data are presented for these time intervals. They believed that under the conditions of their experiments, which included carefully measured diet and fluid intake, there was an increase both in the extracellular and intracellular fluid volumes. They further stated, "It would appear therefore that alcohol has an effect on the renal epithelium allowing the water to pass but holding back potassium in large amounts and sodium, chloride, and nitrogen in smaller amounts. When the potassium and nitrogen are considered it appears that the effect of alcohol is not unlike that noted for the absence of adrenal cortical hormone. During the recovery phase, potassium, sodium, chloride, and nitrogen were lost in greater amounts than they were taken in. Since the loss occurred when the concentration of alcohol in the blood had fallen to lower levels it would appear that the barrier to the excretion of these substances had been removed."

The most recent studies are those of Eggleton (10-12), whose subjects ingested alcohol diluted with considerable quantities of cider usually a few hours after breakfast. Her findings are in essential agreement with those to be reported below. In one volunteer who cooperated in 15 experiments, it appeared that approximately $100 \mathrm{ml}$. of extra urine were produced for each $10 \mathrm{ml}$. of alcohol ingested.

In view of the lack of agreement in the literature, the problem of whether alcohol is diuretic and if so, the nature of the diuresis and its mechanism seemed worthy of investigation, particularly since Nicholson and Taylor (9) concluded that alcohol directly affects the renal epithelium. Further, it would appear that there was need for acute experiments in which the possible effects of alcohol 
in altering the speed of absorption of food, water and electrolyte from the gastro-intestinal tract were obviated by utilizing subjects in the postabsorptive state.

\section{METHODS}

The subjects, healthy adults, unaccustomed to the intemperate use of strong drink, were volunteers. They ate their breakfast, including approximately $800 \mathrm{ml}$. of liquids, prior to 7:15 a.m. ${ }^{5}$ Urine was passed as desired until 10:15 a.m. when the bladder was emptied. At $12: 15$ p.m., the bladder was again emptied, blood obtained for analysis, and within a period of four to six minutes $147 \mathrm{ml}$. of 86 proof Bourbon whiskey was ingested $(50 \mathrm{gm}$. of absolute alcohol). In control experiments an equal quantity of water was taken instead of the whiskey. Blood and urine were again collected two and four hours later, and a final urine collection obtained at six hours.

Prior to withdrawing blood without stasis from an antecubital vein, the arm was immersed in hot water for 10 minutes to arterialize the blood (16) and avoid any possible differences between control and whiskey runs due to the peripheral vasodilating effect of the latter.

Hematocrits were measured by the Wintrobe technique (17), hemoglobin with a photoelectric colorimeter on blood rendered incoagulable by a mixture of ammonium and potassium oxalate. Blood for electrolyte examination was collected under oil and serum separated by centrifugalization. Serum and urine chloride were determined by the Volhard titration (18), sodium and potassium with the Barclay internal standard flame photometer. Creatinine was measured in serum and urine by Peters modification (19) of the Folin technique.

${ }^{5}$ It would be ideal, in studying electrolyte excretion, to commence with the subject in a basal or steady state. However, no such state appears to occur in man. The maintenance of subjects on a constant dietary and fluid intake for at least a fortnight does not prevent large and inexplicable fluctuations in salt and water excretion from day to day (13). The use of early morning periods is particularly hazardous since it has been observed that there is a nocturnal suppression of salt excretion even when water intake is maintained constant, followed by a morning rise (14). This occurs whether the subject remains asleep, awake in bed or up and about. It occurs in patients who have been bedridden for weeks or in ambulatory subjects. It is uninfluenced except in absolute magnitude, by previous high, moderate, or extremely low salt intakes (15), and has not infrequently led investigators to conclude that some therapeutic procedure employed was responsible for the effects observed. In our experience, a reasonably constant rate of decline in salt excretion occurs during an eight hour period commencing in the late morning after an early breakfast, when lunch is omitted. Accordingly this period was chosen for study.

\section{RESULTS}

In Figures 1-3, the effects of $147 \mathrm{ml}$. of tap water are contrasted with the effects of a similar quantity of 86 proof Bourbon whiskey. It will be observed that in each instance there was a marked augmentation of urine flow during the first two hours after the whiskey ingestion, unaccompanied by any increase in electrolyte excretion. In the following four hours there was no conspicuous difference in urine flow from that observed in the control periods, although there appeared to be a slight increase in the rate of electrolyte excretion, with proportionately more sodium excreted than chloride. The changes in serum sodium are within the limits of error of the method. The steady rise in serum chloride is probably of significance. No changes of note occurred in hematocrit, hemoglobin, endogenous creatinine clearance, or potassium in serum and urine.

These data indicate that under the conditions of the experiments, the ingestion of $50 \mathrm{gm}$. of ethyl alcohol in the form of Bourbon whiskey led to an increased urinary excretion of water. Since endogenous creatinine clearance was unchanged it appears probable that this was not due to an increase in glomerular filtration rate but rather to decreased tubular reabsorption of water.

Pure water diuresis of this type is ordinarily encountered only after the ingestion or injection of water or hypotonic solutions, where it serves to

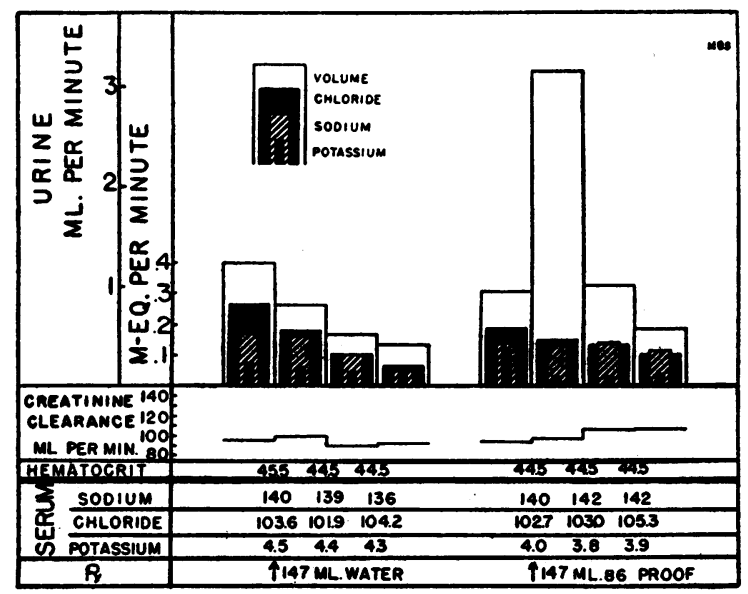

Fig. 1. Comparative Efrects of Water and Whiskey INGESTION

Each urine collection period was of two hours' duration. Blood samples were obtained before and two and four hours after the ingestion of either water or whiskey. 
maintain homeostasis. It is presumably due to decreased secretion of anti-diuretic hormone by the supra-optico-hypophyseal mechanism. Alcohol might produce a pure water diuresis by a direct effect on the renal tubular epithelium, inhibiting water reabsorption or it might inactivate circulating anti-diuretic hormone. Accordingly, in the next two experiments, 1 unit of posterior pituitary extract (Pitressin, Parke, Davis \& Co.) was injected subcutaneously at the time of whiskey ingestion. Figures 4 and 5 illustrate clearly that

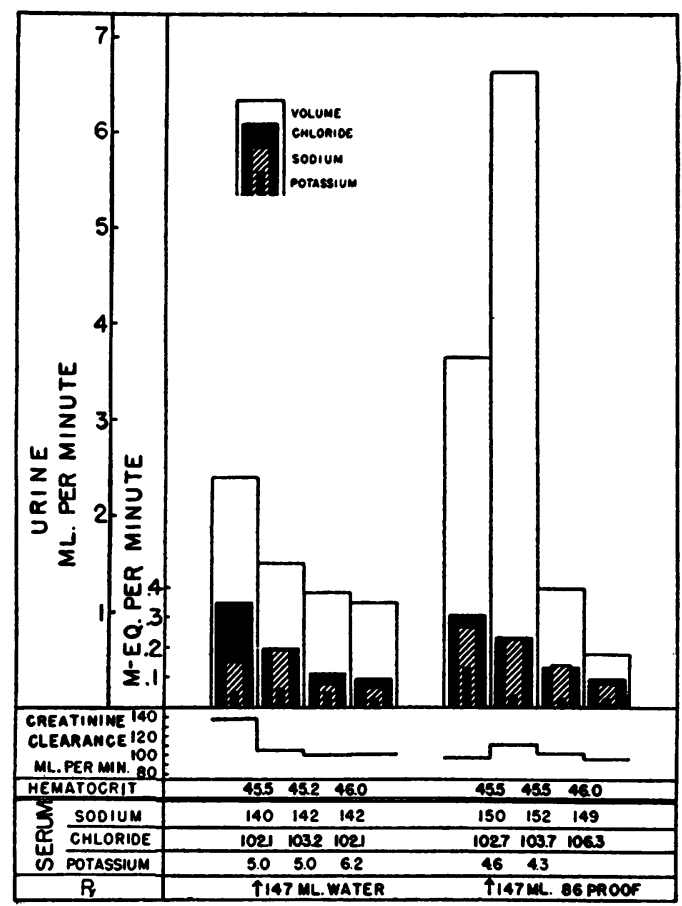

Fig. 2. Comparative Effects of Water and WHISKEY INGESTION

Each urine collection period was of two hours' duration. Blood samples were obtained before and two and four hours after the ingestion of either water or whiskey.

diuresis is inhibited for the first two hours and is not striking during the next four hours. This is approximately the length of time and the magnitude of inhibition of diuresis to be expected from this dose of pituitary extract in the absence of alcohol ingestion.

These data indicate that the renal tubular epithelium is capable of responding to exogenous anti-diuretic hormone and provide no evidence that the latter is inactivated by alcohol in the dose employed.

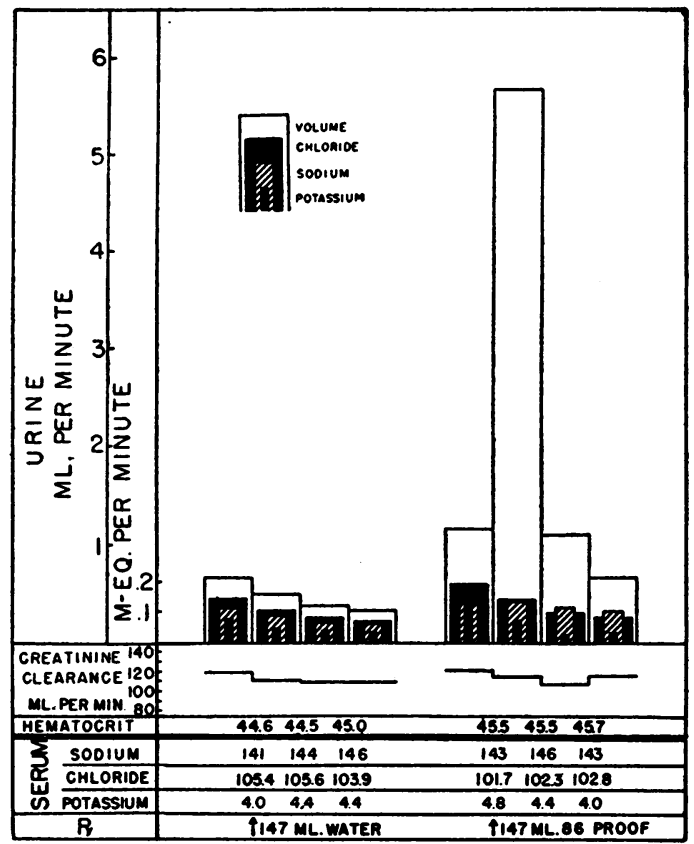

Fig. 3. Comparative Effects of Water and WHISKEY INGESTION

Each urine collection period was of two hours' duration. Blood samples were obtained before and two and four hours after the ingestion of either water or whiskey.

The supra-optico-hypophyseal mechanism normally responds to the stimulus of hypertonicity (20). Accordingly, 200 m.eq. of dry $\mathrm{NaCl}$ on $90 \mathrm{gm}$. of celery was ingested just prior to the Bourbon (Figure 4) or 20 minutes after the Bourbon (Figure 5). Inhibition of diuresis is apparent.

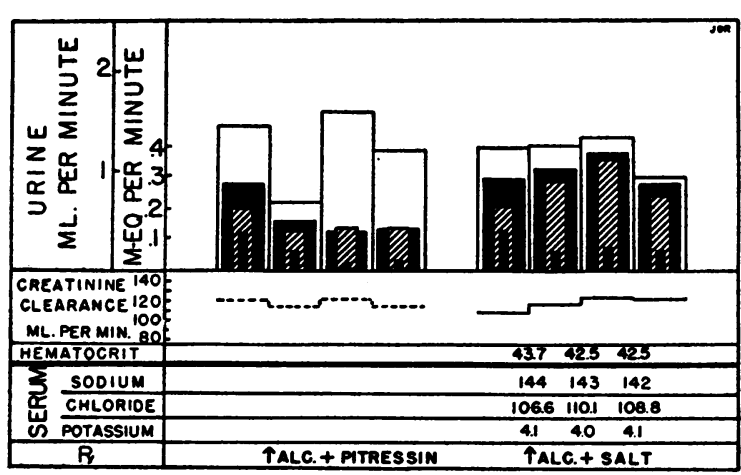

Fig. 4. The Effect of Pitressin and Sodium Chloride on Alcohol Diuresis

(Broken line indicates creatinine clearance estimated by assuming serum concentration of $1.0 \mathrm{mg}$. per $100 \mathrm{ml}$.) 


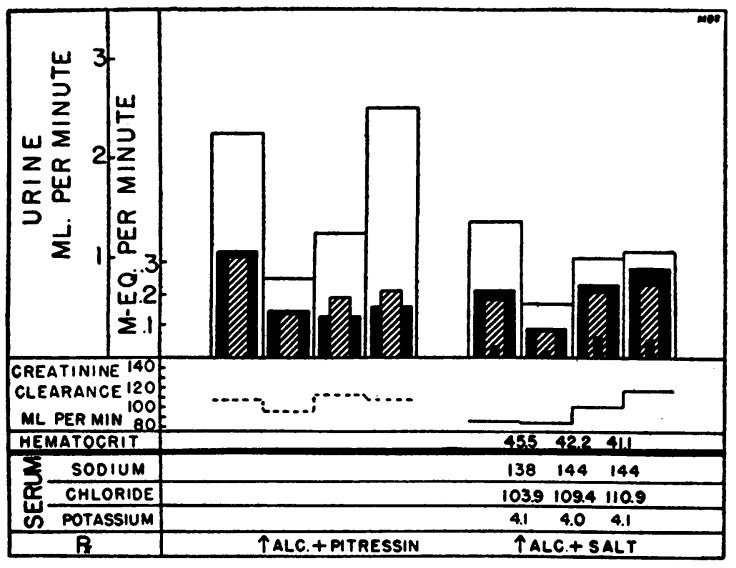

Fig. 5. The Effect of Pitressin and Sodium Chloride on Alcohol Diuresis

(Broken line indicates creatinine clearance estimated by assuming serum concentration of $1.0 \mathrm{mg}$. per $100 \mathrm{ml}$.)

It is thus apparent that alcohol in the dose employed does not eliminate the response of the supra-optico-hypophyseal mechanism to hypertonicity nor prevent the usual renal tubular response.

Since it had been shown that alcohol leads to a water diuresis unaccompanied by an equivalent loss of electrolyte it was of interest to determine how the administration of a considerable volume of water shortly after the alcohol would affect this phenomenon. Accordingly, the three subjects each ingested $853 \mathrm{ml}$. of tap water 20 minutes after imbibing $147 \mathrm{ml}$. of whiskey. Although the maximum diuretic rate was only slightly increased by this procedure, increased flow continued for four or more hours, so that the total urine volume was greatly increased; in fact the total water loss was in each case more than $1000 \mathrm{ml}$. greater than that of the control period. (Table I.)

It would thus appear that following alcohol in-

TABLE I

\begin{tabular}{|c|c|c|c|}
\hline \multirow{2}{*}{ Subject } & \multicolumn{3}{|c|}{ Urine volume during six hrs. following: } \\
\hline & $147 \mathrm{ml}$. water & $147 \mathrm{ml}$. whiskey & $\begin{array}{l}147 \mathrm{ml} \text {. whiskey } \\
+853 \mathrm{ml} \text {. water }\end{array}$ \\
\hline $\begin{array}{l}\text { No. } 1 \\
\text { No. } 2 \\
\text { No. } 3\end{array}$ & $\begin{array}{c}m l . \\
218 \\
330 \\
146\end{array}$ & $\begin{array}{r}m l . \\
578 \\
1018 \\
892\end{array}$ & $\begin{array}{c}m l . \\
1627 \\
1374 \\
1364\end{array}$ \\
\hline Average & 231 & 829 & 1455 \\
\hline
\end{tabular}

gestion the supra-optico-hypophyseal mechanism responds to the stimulus of hypotonicity but the water loss is excessive, suggesting a quantitatively altered reactivity.

Total excretion of $\mathrm{Na}, \mathrm{K}$, and $\mathrm{Cl}$ and net water balance have been averaged for the three subjects during the control, whiskey, and whiskey and water experiments (Figure 6). The net water balance has been calculated on the assumption that each subject sustained an insensible loss of 300 ml. during the six hour period. This value is be-

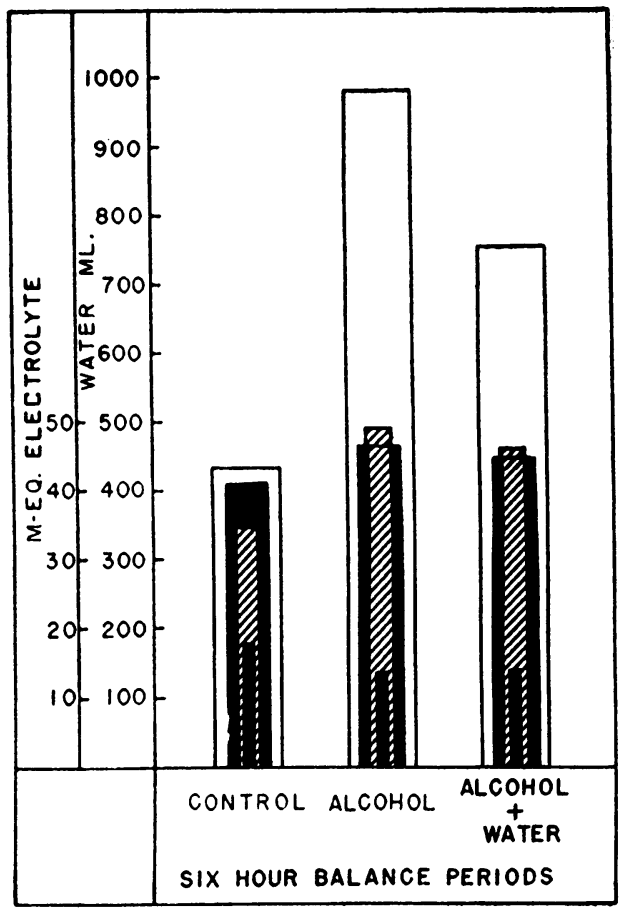

Fig. 6. Net Balances of Water and Electrolytes During Six Hours after the Ingestion of 147 ML. of WATER, 147 ML. OF Bourbon WhisKey, AND 147 ML. OF Whiskey Followed by 853 ML. OF WAter

lieved to be a reasonable approximation since it is the average value obtained by careful weighing in another group of experiments. Since the metabolism of 1 mole of alcohol ( $46 \mathrm{gm}$.) gives rise to 3 moles of water ( $48 \mathrm{gm}$.), the whiskey was considered the equivalent of water for the calculation of the balance. Since probably all the alcohol was not metabolized during the six hours and since the insensible loss of water may be increased by alcohol ingestion, the net balances, if in error, represent an underestimate of the water loss. It is ap- 
parent from the figure that the ingestion of $853 \mathrm{ml}$. of water after the whiskey reduces the magnitude of the negative water balance induced by whiskey alone but does not abolish it. ${ }^{6}$ The slightly increased excretion of chloride over the control value and the definitely increased excretion of sodium appear to be due to their increased excretion in the last four hours of the six hours following alcohol ingestion.

\section{DISCUSSION}

Data presented above clearly demonstrate that $147 \mathrm{ml}$. of 86 proof Bourbon whiskey administered in the post-absorptive state five hours after breakfast leads to a water diuresis within the next two hours. Since we have observed that pure ethyl alcohol given intravenously has similar effects, there is reason to believe that it is the alcohol rather than other ingredients in the whiskey which was responsible. We have not employed pure diluted alcohol by mouth because of its unpalatability and the knowledge that unpleasant stimuli of any kind may stimulate anti-diuretic activity.

The observations reported here are not in conflict with those of Mendel and Hilditch (6) or Nicholson and Taylor (9), who administered repeated doses of alcohol with and between meals over a prolonged period of time. Under such conditions the level of blood alcohol probably never is as high as with the smaller total dose administered on an empty stomach within six minutes. Moreover under their experimental conditions short periods of diuresis might have been masked.

There is no evidence from our observations that the excretion of $\mathrm{Na}, \mathrm{K}$, or $\mathrm{Cl}$ is affected during the period when maximum water diuresis occurs. The apparent increase in excretion of $\mathrm{Na}$ and $\mathrm{Cl}$ during the last four hours of the six hour postalcohol period may well represent a compensatory mechanism to restore normal electrolyte values following the water diuresis.

Although the mechanism of whiskey diuresis has not been established, its resemblance to water diuresis and its inhibition by pituitary extract or salt ingestion suggest as a working hypothesis

${ }^{6}$ However, other experiments indicate that a sufficiently large quantity of water (several liters) will eliminate the negative balance or convert it to a positive one. that it is due to a depression of normal supraoptico-hypophyseal responsiveness to alterations in tonicity.

\section{CONCLUSIONS}

1. One hundred and forty-seven $\mathrm{ml}$. of 86 proof Bourbon whiskey ( $50 \mathrm{gm}$. alcohol) administered in the post-absorptive state over a short period of time, provokes water diuresis similar to that obtaining after water ingestion, but differing in that the latter leads to maintaining isotonicity of the body fluids whereas whiskey diuresis leads to hypertonicity.

2. The ingestion of $853 \mathrm{ml}$. of water shortly after whiskey does not prevent a loss of body water in excess of electrolyte.

3. Whiskey diuresis is not due to an increase in glomerular filtration rate.

4. Whiskey diuresis can be inhibited for at least several hours by the subcutaneous injection of 1 unit of pitressin.

5. Whiskey does not prevent the supra-opticohypophyseal response to hypertonicity induced by the ingestion of dry sodium chloride.

6. It is suggested that the locus of action of whiskey may be on the supra-optico-hypophyseal mechanism rather than on the kidney tubules.

\section{ACKNOWLEDGMENT}

The technical assistance of Miss Elsie C. Rossmeisl and Miss Eleanor G. Morrill is gratefully acknowledged.

\section{BIBLIOGRAPHY}

1. Shakespeare, W., Macbeth, II, 3.

2. Cushny, A. R., Pharmacology and Therapeutics. 12th Ed., revised by C. W. Edmunds and J. A. Gunn. Lea \& Febiger, Philadelphia, 1940.

3. Goodman, L., and Gilman, A., The Pharmacological Basis of Therapeutics. Macmillan Co., New York, 1941.

4. Simanowsky, N. P., Ueber die Gesundheitsschädlichkeit hefetrüber Biere und über den Ablauf der künstlichen Verdauung bei Bierzusatz. Arch. für Hyg., 1886, 4, 1.

5. Raphael, A., Ueber die diuretische Wirkung einiger Mittel auf den Menschen. Arb. d. pharmakol. Inst. zu Dorpat., Stuttg., 1894, 10, 81.

6. Mendel, L. B., and Hilditch, W. W., The influence of alcohol upon nitrogenous metabolism in men and animals. Am. J. Physiol., 1910, 27, 1. 
7. Miles, W. R., The comparative concentrations of alcohol in human blood and urine at intervals after ingestion. J. Pharm. \& Exper. Therap., 1922, 20, 265.

8. Bruger, M., The effects of alcohol on the normal and pathologic kidney: a review. Quart. J. Studies on Alcohol, 1940, 1, 85.

9. Nicholson, W. M., and Taylor, H. M., The effect of alcohol on the water and electrolyte balance in man. J. Clin. Invest., 1938, 17, 279.

10. Eggleton, M. G., The diuretic action of alcohol in man. J. Physiol., 1942, 101, 172.

11. Eggleton, M. G., Urine acidity in alcohol diuresis in man. J. Physiol., 1946, 104, 312.

12. Eggleton, M. G., and Smith, I. G., The effect of ethyl alcohol and some other diuretics on chloride excretion in man. J. Physiol., 1946, 104, 435.

13. Atchley, D. W., Loeb, R. F., Richards, D. W., Jr., Benedict, E. M., and Driscoll, M. E., On diabetic acidosis; detailed study of electrolyte balances following withdrawal and reestablishment of insulin therapy. J. Clin. Invest., 1933, 12, 297.

14. Norn, M., Untersuchungen über das Verhalten des
Kaliums im Organismus. II. Ueber Schwankungen der Kalium-, Natrium- und Chloridausscheidung durch die Niere im Laufe des Tages. Skandin. Arch. f. Physiol., 1929, 55, 184.

15. Strauss, M. B., and Schwartz, W. B., Unpublished observations.

16. Meakins, J. C., and Davies, H. W., Observations on the gases in human arterial and venous blood. $\mathrm{J}$. Path. \& Bact., 1920, 23, 451.

17. Wintrobe, M. M., The size and hemoglobin content of the erythrocyte; methods of determination and clinical application. J. Lab. \& Clin. Med., 1932, 17, 899.

18. Peters, J. P., and Van Slyke, D. D., Quantitative Clinical Chemistry. Volume II. Methods. Williams and Wilkins, Baltimore, 1932, pp. 833-835 and 838-839.

19. Peters, J. H., The determination of creatinine and creatine in blood and urine with photoelectric colorimeter. J. Biol. Chem., 1942, 146, 179.

20. Verney, E. B., Absorption and excretion of water. The antidiuretic hormone. Lancet, 1946, 2, 739, 781. 